\title{
Pedagogia da Variação Linguística: por uma abordagem heterogênea da língua a fim de minimizar o preconceito linguístico
}

Pedagogy of Language Variation: to an heterogeneous approach OF LANGUAGE TO MINIMIZE THE LANGUAGE PREJUDICE

\section{Taciane Marcelle MARQUES * Joyce Elaine de ALMEIDA BARONAS **}

Resumo: O preconceito linguístico ocorre em diversos ambientes e sua propagação resultará cada vez mais na repetição da ideia de que o brasileiro não sabe a própria língua, que não a usa corretamente. Esse preconceito também pode ser relativo à abordagem das normas não padrão em sala de aula juntamente com a padrão. Dessa forma, justificamos este trabalho, pois é função das instituições escolares fornecer um ensino de Língua Portuguesa livre de preconceito linguístico. O presente artigo tem como objetivo (i) observar as atitudes positiva ou negativa a respeito do uso das variedades linguísticas e (ii) demonstrar a necessidade de abordar a variação linguística nas instituições escolares a fim de minimizar a ocorrência do preconceito linguístico entre os falantes da heterogênea língua portuguesa. Esta pesquisa verificou que o estudo da variação linguística já se faz presente na escola, mas ainda não o suficiente, visto que nem sempre os alunos são capazes de

* Doutoranda do Programa de Pós-Graduação em Estudos da Linguagem da Universidade Estadual de Londrina, na área de Linguagem e Educação. Mestre em Estudos da Linguagem pela UEL (2013). Bolsista CAPES. Contato: taciane.marcelle@gmail.com.

** Pós-Doutorado pela Universidade de Brasília (2014). Doutorado em Linguística e Língua Portuguesa pela Universidade Estadual Paulista Júlio de Mesquita Filho, Araraquara (2005). Docente na Universidade Estadual de Londrina. Contato: joyal@uel.br. 
identificar as variedades de fato. Portanto, é necessário um maior cuidado para tratar de peculiariedades linguísticas a fim de evitar atitudes negativas quanto a essa abordagem e, consequentemente, minimizar o preconceito linguístico.

Palavras-chave: Sociolinguística. Preconceito. Pedagogia da variação.

Abstract: The linguistic prejudice occurs in differents environments and its dissemination will result more and more in the repetition of the idea that the Brazilian does not know his own language, and he does not use it correctly. This prejudice may be also related to the approach of non standard and the standard norms together in the classroom. Thus, we justify this paper, for it is role of educational institutions to provide the teaching of the Portuguese language free of linguistic prejudice. This present work aims (i) to observe the positive attitudes and the negative one, regarding to the use of linguistic variations and (ii) to demonstrate the necessity of approach the linguistic variation in the educational institutions in order to minimize the incidence of linguistic prejudice among the speakers of the heterogeneous Portuguese language. This research has found that the study of linguistic variation is already actual in the school but it is not enough, considering that students are not always possible to really identify the varieties of fact. Therefore it is necessary a greater care to treat the linguistic peculiarities in order to avoid negative attitudes with this approach, and consequently minimize linguistic prejudice.

Key words: Sociolinguistics. Prejudice. Pedagogy of variation.

\section{Considerações Iniciais}

A multiplicidade da língua portuguesa exige uma abordagem dessa variação nas escolas, de forma a evitar o estímulo do preconceito linguístico, pois os alunos seriam capazes de compreender os diversos usos linguísticos adequados a diferentes situações. A escolha e o uso de determinada forma linguística estão relacionados a fatores extralinguísticos e, justamente por isso, 
os Parâmetros Curriculares Nacionais (PCN) defendem que "não se pode mais insistir na idéia de que o modelo de correção estabelecido pela gramática tradicional seja o nível padrão de língua ou que corresponda à variedade lingüística de prestígio" (BRASIL, 1998, p. 31). Entretanto, como o preconceito é decorrente do valor atribuído à variedade padrão e também do estigma associado às variedades não padrão, nomeadas como erradas pela gramática normativa da língua, destacamos que as variedades linguísticas são esquecidas e deixadas de lado como objeto de ensino na maioria das aulas de Língua Portuguesa. É função das instituições escolares proporcionar um ensino da Língua Portuguesa mantendo a noção de língua como um conjunto de variedades. Tal constatação constitui, pois, a justificativa deste trabalho, visto que investigar crenças e atitudes linguísticas dos alunos em relação à língua e ao ensino da língua ajudaria a revelar os sentimentos de valoração positiva ou negativa, ou seja, as crenças e atitudes linguísticas que interferem no uso das variedades e, principalmente, na abordagem dessas em contexto escolar.

O presente estudo pretende (i) observar as atitudes positiva ou negativa dos alunos de ensino fundamental a respeito do uso das variedades linguísticas e (ii) demonstrar a necessidade de abordar a variação linguística nas instituições escolares a fim de minimizar a ocorrência do preconceito linguístico entre os falantes da heterogênea língua portuguesa.

\section{Norma Padrão e Variação Linguística}

Convém destacar e definir "norma padrão" e "variação línguística", visto tais conceitos estarem diretamente relacionados ao preconceito linguístico. A discussão a respeito do tema da variação linguística se mostra necessária em diversos ambientes, inclusive o escolar. Faraco (2002) já havia afirmado:

Se como resultado da intervenção dos lingüistas, o tema da variação acabou incorporado pelo discurso pedagógico, podemos dizer que não conseguimos ainda construir uma pedagogia adequada a essa área. Talvez porque não tenhamos ainda, como sociedade, discutido suficientemente, no espaço público, nossa heterogênea realidade lingüística, nem a violência simbólica que a atravessa. (FARACO, 2008, p. 177). 
Coseriu (1987) considera a norma como o aspecto do falar que representa a tradicão cultural e social. Isso se verifica quando o autor distingue norma de sistema, abordando a norma como aquilo que é imposto, por uma tradição, ao indivíduo:

Com efeito, vimos que o que se impõe ao falante não é o sistema (que "se lhe oferece"), mas a norma. Pois bem, o falante tem consciência do sistema, e o utiliza, e, por outro lado, conhece ou não conhece, obedece ou não obedece à norma, mesmo mantendo-se dentro das possibilidades do sistema. Mas a originalidade expressiva do indivíduo que não conhece ou não obedece à norma pode ser tomada como modelo por outro indivíduo, pode ser imitada e tornar-se, por conseguinte, norma. O indivíduo, pois, altera a norma, ficando dentro dos limites permitidos pelo sistema; mas a norma reflete o equilíbrio do sistema num determinado momento e alterando a norma, altera esse equilíbrio, até pender totalmente para um lado ou para o outro. (COSERIU, 1987, p. 80).

Faraco (2008) comenta a proposta de Coseriu (1987), afirmando que esse estudioso modifica a perspectiva saussureana dicotômica (langue/parole, sistema/fala) transformando-a em uma perspectiva tricotômica (sistema/ norma/fala). Assim, a definição de norma elaborada por Coseriu (1987) indica um olhar estruturalista de inspiração saussureana. A norma seria, dessa forma, "cada um dos diferentes modos sociais de realizar os grandes esquemas de relações do sistema" (FARACO, 2008, p. 34).

Entendemos, ainda, que a norma padrão é imposta ao indivíduo, contudo, o indivíduo pode alterar a norma, gerando outra que será também obedecida pelos integrantes da mesma comunidade de fala, levando em conta os aspectos social e cultural.

Ao considerar a afirmação de Câmara Jr. (1970), de que a gramática, desde a greco-latina, era normativa, sobretudo, como uma "arte de falar e escrever corretamente” (CÂMARA JUNIOR, 1970, p. 15), podemos compreender que a norma padrão da Língua Portuguesa seria uma maneira de escrever e falar nessa língua de forma a adotar suas regras existentes, como as formas linguísticas postas como culta por um grupo 
socioeconomicamente favorecido e, por isso, vista como padrão com o decorrer do tempo. Faraco (2008) também aborda esses conceitos a partir dos termos norma culta e norma padrão. Castilho (2002) comenta a ideia de norma a partir de dois conceitos: amplo e estrito De um lado, o conceito amplo da norma, ou seja, um fator de coesão social, visto que é próprio das comunidades linguísticas corrigir os desvios da norma e, por outro lado, o conceito estrito, os usos e as aspirações da classe social de prestígio. $\mathrm{O}$ primeiro conceito de norma aponta para a compreensão de que a língua serve como um elo social para os indivíduos. Rosenbkatt (1967, p. 117 apud CASTILHO, 2002, p. 29) destaca que a língua "é ao mesmo tempo fator da coesão social e alvo das pressões da sociedade, ciosa de preservar sua identidade", por meio de atitudes linguísticas que se realizam a partir das regras do bom uso.

No caso da norma como conceito estrito, Castilho (2002) distingue norma objetiva, norma subjetiva e norma prescritiva. A norma objetiva, explícita ou padrão ideal, é a linguagem usada pela classe social de prestígio, pela classe culta, escolarizada, e é caracterizada como prestigiosa pela classe social a que está relacionada. Já a atitude dos falantes em relação à norma objetiva é nomeada pelo autor de norma subjetiva, implícita ou padrão ideal, ou seja, trata-se do que as pessoas esperam que as outras "digam em determinadas situações” (RODRIGUES, 1968, p. 46 apud CASTILHO, 2002 , p. 30). E a combinação dessas normas (objetiva e subjetiva) resulta na norma prescritiva. A norma prescritiva corresponde, portanto, à prescrição dos "usos linguísticos de uma classe prestigiosa considerados mais adequados a cada situação e melhor identificados com o ideal de perfeição linguística" (CASTILHO, 2002, p. 30). Dessa forma, o caráter unificador da norma prescritiva, segundo o autor, é o principal motivo de ser impositiva, continuando, ainda assim, sujeita a variações.

Castilho (2002, p. 30) salienta que a norma, em seu conceito mais estrito, é aquela de maior interesse para o ensino, visto que as normas objetiva, subjetiva e prescritiva revelam "os usos e atitudes de uma classe social de prestígio”. A partir dessas distinções, o autor constata que existe uma norma escrita, mais conservadora, distinta da norma oral, mais inovadora, visto que as atitudes mudam com o tempo. Assim, é preciso buscar a norma relacionada a cada época em seu próprio período e em sua norma prescritiva. Ao considerar tanto a norma culta, devido à importância do espaço social a 
que essa se relaciona, como a pluralidade de normas, especialmente as orais, devido à expansão territorial do país e seu rápido processo de urbanização, ele apresenta dois registros, respectivamente, a norma refletida e a norma coloquial.

Faraco (2002) defende que, em uma sociedade como a brasileira, existem inúmeras normas linguísticas. Portanto, a norma, qualquer que seja, é a junção de um conjunto de formas linguísticas, bem como um agregado de valores socioculturais. Dentre as normas, destaca a "norma padrão" e a "norma culta". Essa última é compreendida pelo autor como aquela "praticada, em determinadas situações (aquelas que envolvem certo grau de formalidade), por aqueles grupos sociais mais diretamente relacionados com a cultura escrita, em especial por aquela legitimada historicamente pelos grupos que controlam o poder social" (FARACO, 2002, p. 39). A norma culta, da parte de seus próprios falantes, produz julgamentos linguísticos de desprestígio, como o de que os falantes de outras normas "não sabem falar', 'falam mal', 'falam errado', 'são incultos', 'são ignorantes' etc." (FARACO, 2002, p. 39).

A "norma padrão" é desencadeada ao longo da história, como sugere o autor, a partir da associação da cultura escrita com o poder social. Essa norma padrão, por sua vez, visou e visa a uma relativa estabilização linguística, com a intenção de neutralizar a variação e controlar a mudança linguística, facilitando a comunicação entre os falantes da nação.

Diante dessas definições, destacamos que a norma culta está muito mais próxima da norma padrão do que as outras. Isto porque, como sugere Faraco (2002), os responsáveis pela implantação e manutenção da norma padrão estão inseridos em grupos sociais, compostos de usuários da norma culta. $\mathrm{O}$ autor ainda aponta o fator histórico, responsável por distanciar a norma culta da norma padrão, em especial no Português Brasileiro (PB), posto que a norma padrão foi construída artificialmente, em sua origem, desconsiderando a norma culta que se utilizava no país. O pesquisador explica esse fato mostrando como foi codificada a língua brasileira:

A codificação que se fez aqui, na segunda metade do século XIX, não tomou a norma culta brasileira de então como refência. Bem ao contrário: a elite letrada conservadora se empenhou em fixar como 
nosso padrão um certo modelo lusitano de escrita, praticado por alguns escritores portugueses do Romantismo (cf. Pagotto, 1998; Faraco, 2002). O modelo não foi, portanto, a língua de Portugal, como muitos pensam, imaginando uma homegeneidade que, de fato, não existe, já que o português de lá é, como qualquer língua, um emaranhado de variedades. (FARACO, 2002, p. 42-43).

Dessa forma, observamos, já no início da língua imposta no Brasil, o distanciamento existente entre a norma culta e a norma padrão artificialmente codificada e assim concebida com base em uma atitude purista e normativa, como afirma o autor. Convém destacar que a atitude de condenar qualquer uso não purista ou normativo vem prejudicando o ensino, considerando que a norma padrão se tornou fator de exclusão social e discriminação linguística.

Faraco (2008), ao atentar para a norma em três abordagens diferentes (estruturalista, gerativista e variacionista), apresenta uma definição significativa revelando que todas consideram a organização de seu sistema:

Toda e qualquer norma (toda e qualquer variedade constitutiva de uma lingua) é dotada de organização. Cada abordagem teórica construirá, a partir de seus pressupostos gerais, um modelo diferente dessa organização - num, cada norma será entendida como um certo arranjo das grandes relações sistemáticas; noutro, como a materialização de uma determinada gramática (de um certo conjunto de princípios e regras); no terceiro, como determinada conjunção de uma certa combinação de regras variáveis. No entanto, nenhuma teoria deixa de reconhecer o fato básico: não há norma sem organização. (FARACO, 2008, p. 35-36).

Ponderando a existência de várias normas linguísticas para a mesma comunidade de fala, é válido destacar que "não existe, em suma, uma norma "pura", como aponta Faraco (2008, p. 42); as normas absorvem características umas das outras - elas são, portanto, sempre hibridizadas. Por isso, não é possível estabelecer com absoluta nitidez e precisão os limites de cada uma das normas". 
Além de cada comunidade apresentar várias normas, ele defende que cada falante domina mais de uma norma e que, se necessário, para se adaptar às redes de atividades "mudará sua forma de falar (sua norma) variavelmente de acordo com as redes de atividades e relacionamentos em que se situa" (FARACO, 2008, p. 41).

Contudo, ao mesmo tempo em que o indivíduo precisa se adaptar a novas redes de atividades por meio da linguagem, ele também é capaz de modificar qualquer norma, fazendo transformações aceitas e utilizadas por outros indivíduos. Dessa forma, afirma o autor que "uma norma, qualquer que seja, não pode ser compreendida apenas como um conjunto de formas lingüísticas; ela é também (e principalmente) um agregado de valores socioculturais articulados com aquelas formas" (FARACO, 2008, p. 41).

Existe, portanto, com relação às normas, uma hierarquização social e uma diferenciação qualitativa. Para o pesquisador, "esta diferenciação ocorre e é feita por determinados segmentos da sociedade tomando por base valores socioculturais e políticos" (FARACO, 2008, p. 54). Mas, de todas as diferenciações, ou ainda, designações adjuntas à norma, a mais complexa é a norma culta, pois há, com relação a esse termo, um emaranhado de pressupostos e atitudes por vezes não discerníveis.

Faraco (2008) sugere uma comparação entre a norma culta e a norma padrão, explicitando como, respectivamente, norma do letrado e norma de um construto sócio-histórico, de um instrumento normativo.

Se a norma culta/comum/standard é a variedade que os letrados usam correntemente em suas práticas mais monitoradas de fala e escrita, a norma-padrão não é propriamente uma variedade da língua, mas como bem destaca Bagno (2007a) - um construto sócio-histórico que serve de referência para estimular um processo de uniformização. (FARACO, 2008, p. 73).

Destacamos que, do ponto de vista gramatical, todas as normas (ou variedades) se equivalem, pois são organizadas e complexas. Entretanto, como bem sugere Faraco (2008), isso não garante que elas se equivalham socialmente. Como exemplo, a norma culta, classificada como a utilizada pelos letrados, ou de prestígio social, não pode ser confundida com a norma padrão, a qual 
corresponde mais a um construto sócio-histórico usado para a criação e permanência da uniformização da língua, comportando suas regras de uso.

Embora ainda haja um senso comum com relação à equivalência entre norma culta e norma padrão, motivo pelo qual linguistas e educadores ainda tomam um conceito pelo outro, destacamos a existência de distinção entre os dois termos. Dessa forma, sintetizando o exposto até aqui sobre o tema, podemos afirmar que a norma culta corresponde a fatos da língua utilizados correntemente por grupos sociais mais ligados à cultura escrita, em situações formais de fala e escrita.

Notamos, então, que a cultura escrita, junto ao poder social, ao longo da história, resulta em um processo fortemente unificador, buscando relativa estabilização linguística, neutralizando a variação e controlando a mudança, que denominamos de norma padrão, isto é, a norma que busca uma estabilização linguística para facilitar a comunicação entre os falantes da língua a que pertence.

Quando, por fim, a norma em julgamento não é a padrão, nem a culta, mas sim uma que possui variantes para um termo, observamos o desenvolvimento por parte do falante de uma atitude linguística de prestígio ou não em relação às variedades, dependendo de suas crenças já construídas. "Assim, algumas variedades recebem avaliação social positiva, enquanto outras são desprestigiadas e até estigmatizadas" (FARACO, 2008, p. 72). E essas valorações expressas pelos falantes sobre a linguagem resultam a partir de relações sociais constituídas sócio-historicamente nas redes de atividades linguísticas em que os falantes estão envolvidos.

Com relação ao conceito de variação linguística, ressaltamos que tal fenômeno pode conduzir ao da mudança; segundo Camacho (1998), quando existem duas ou mais variantes em competição, uma delas acabará por vencer a outra, modificando a língua. Os estudos que prezam pela relação entre língua e sociedade desenvolvem pesquisas envolvendo e utilizando a categorização a partir de fatores extralinguísticos, tais como classe social, idade, sexo, escolaridade, entre outros.

Para definir esse fenômeno, Camacho (1988, p. 29) comenta que cada sujeito tem seu modo de falar e que "a linguagem humana varia de acordo com o grau de contato entre os seres que constituem a comunidade universal"; além disso, afirma existirem diferenças tanto entre os idiomas, que "identificam 
os nativos de uma nação" quanto entre grupos menores, pois a língua "se transforma no tempo e se diversifica no espaço". A variação existe em diferentes lugares e também pode ser utilizada pelos mesmos indivíduos, em diferentes situações de comunicação, adequando-se à sua necessidade.

As línguas, de acordo com Castilho (2010), são heterogêneas, visto que ajudam o sujeito a dar conta das muitas situações sociais em que se envolve, e precisam, também, adaptar-se a diversos momentos históricos, por isso, para o autor, são predispostas à mudança, visto que os grupos humanos são dinâmicos. Mesmo com variação e mudança na língua, há comunicação eficiente entre o locutor e o interlocutor; dessa forma, ainda de acordo com Catilho (2010), eles fazem suas escolhas no multissistema linguístico, deixando sua marca ao escolher uma variante ou outra.

As variantes linguísticas compõem, segundo o autor, cada conjunto de variação, tais como variação sociocultural, variação geográfica, variação de canal, entre outras.

Com isso, entende-se por variação a manifestação concreta da língua, e por variedade a soma idealizada das variações. Se fôssemos dispor esses conceitos numa hierarquia, teríamos: variante $>$ variação $>$ variedade. (CASTILHO, 2010, p. 197).

Os tipos de variação linguística podem ser classificados, considerando seu caráter pedagógico tanto para pesquisas quanto para o ensino, de acordo com a proposta do pesquisador em variação geográfica, sociocultural, individual, de canal e temática. Os tipos de variação coexistem de forma independente da língua, porque a língua é o conjunto de variedades, como já afirmou Faraco (2008). Sobretudo, "não há, como muitas vezes imagina o senso comum, a língua de um lado, e, de outro, as variedades. A língua é em si o conjunto de variedades" (FARACO, 2008, p. 71).

Castilho (2010) apresenta a variação geográfica como um fenômeno de diferenças linguísticas observadas entre regiões. Ponderando que o falante de qualquer língua natural pertence a um espaço geográfico, o autor assevera a existência de uma correlação entre a região de origem dos falantes e as marcas específicas que vão deixando em sua produção linguística. Dessa forma, uma língua natural contém diferentes dialetos relacionados ao espaço geográfico que ocupa. Destacamos a noção de dialeto: 
1.Variedade linguística* especificada por sua distribuição geográfica. O português brasileiro compreende dialetos do Norte (amazônico, paraense), do Nordeste (pernambucano, bahiano), do Sudeste (caipira, carioca), do Centro-Oeste (cuiabano) e do Sul (paranaense, catarinense, gaúcho). (CASTILHO, 2010, p. 671).

Podemos afirmar que dialeto corresponde às variedades regionais assinaladas por diferentes graus de intercompreensão. No Brasil, dentre as possibilidades de variação linguística, a geográfica é uma das mais perceptíveis para os falantes, dada a amplitude territorial do país, sendo perceptível a diferença entre falantes de regiões distintas, pois o falante de outra região de origem possui marcas específicas na produção linguística que difere em sua fala.

Outra forma de variação linguística tão perceptível para o falante quanto a geográfica é a sociocultural, pois o falante também consegue diferenciar a linguagem culta e a popular, optando e mesclando-as em determinandas situações. O fato de cada falante proceder de um segmento diferente da sociedade também pode favorecer a variação da língua. Segundo o autor, para sistematizar as variedades socioculturais, devemos considerar o falante não escolarizado e o falante escolarizado, visto que aqueles normalmente usam o Português popular e estes usam o Português culto. O pesquisador destaca, porém, que nenhum falante é exclusivamente falante popular nem falante culto, já que o que distingue uma variedade de outra é a frequência de uso de uma variante. Assim, o autor revela:

(1) não há uma oposição categórica entre fala popular e fala culta, ocorrendo em muitos casos um compartilhamento de propriedades; (2) em certos casos, a preferência culta exclui fortemente a preferência popular; (3) em situações informais diminui a distância entre essas variedades, e o falante da execução popular, ainda que não em todos os casos; (4) as variedades populares flutuam de acordo com a região geográfica, mas a fala culta é um pouco mais homogênea, sobretudo em sua forma escrita. (CASTILHO, 2010, p. 209).

O estudioso atenta ainda para o fato de essas duas modalidades, a fala popular e a fala culta, terem sido trazidas pelos portugueses, ou seja, elas 
também possuem características da variação diacrônica. E, com relação à norma culta, explica que se tem observado nas diversas comunidades de fala a existência, em qualquer época, de uma variedade linguística de maior prestígio, a norma culta, lembrando que essa variedade sofre mudanças no eixo diacrônico.

Segundo Castilho (2010), a variação individual é observada a partir de um conjunto de parâmetros: o sociocultural, que já foi definido anteriormente, o registro, a idade e o sexo. Quanto ao registro, o pesquisador também aborda de forma isolada na variação de canal, é dividido em formal (ou refletido) e informal (ou coloquial), sendo esses distintos por graus de intimidade entre os falantes, de forma que essa diferenciação é causada pela escolha dos recursos linguísticos adequados a determinadas situações. $\mathrm{Na}$ variação individual por idade, por sua vez, o autor aponta as diferenças entre a linguagem de idosos e de crianças, visto que os idosos falam como antigamente e as crianças utilizam, em sua fala, as mudanças da língua, acatando as variantes novas. Por fim, o autor define a variação relacionada ao sexo, ou seja, quando existem marcas de heterogeneidade entre a fala do homem e da mulher.

A respeito da variação de canal, o pesquisador destaca que as línguas naturais são dialógicas e, por isso, na comunicação, tanto na fala quanto na escrita, o locutor deve considerar o interlocutor, presente ou ausente. O pesquisador propõe um continuum língua falada - língua escrita: Tannen (1982), Chafe (1987, 1994), Biber (1988), Marcuschi (1997). Segundo Castilho (2010), as variedades língua falada e língua escrita não estão cada uma em um polo distinto, mas se dispõem em um continuum, passando da oralidade para a escrituralidade (conversa - conferência, discurso - notícia de jornal - ensaio).

Defende que o Português corrente, aquele com assuntos do dia a dia, e o Português técnico, aquele com assuntos especializados, compõem os exemplos denominados de variação temática, sugerindo como modelo a linguagem do cidadão comum em contraste com a linguagem dos cientistas, dos clérigos, dos políticos, etc.

$\mathrm{O}$ pesquisador indica que termos da linguagem técnica podem ser encontrados no Português corrente, quando a técnica está relacionada a uma atividade de importância social para a comunidade de fala. No Brasil, por exemplo, o pesquisador aponta a importância social do carnaval e do futebol 
e o reflexo sobre a linguagem técnica, pois, devido à importância social desses temas, os indivíduos passam a observar essas práticas e a utilizar essas linguagens técnicas em seu dia a dia.

\section{Variação Linguística na Escola}

A abordagem da diversidade da língua na escola constitui papel muito importante para o docente, uma vez que a forma como o conceito da variação linguística é apresentado aos alunos interfere no posicionamento dele com relação à língua.

Sobre variação linguística e ensino, Camacho (1988) assevera que a função da escola pública é, dentre outras coisas, inculcar nos alunos atitudes linguísticas que não desprestigiem a língua vernácula. Ele ainda aponta que, no ensino, existem momentos pertinentes para mostrar as formas de variação linguística para os alunos, ensinando-lhes que cada variedade tem sua situação adequada de uso, não privilegiando somente a norma padrão. Ao abordar a variação de tal forma, evita-se o estímulo do preconceito linguístico, pois os alunos seriam capazes de compreender os diversos usos linguísticos adequados a diferentes situações.

A escolha e o uso de determinada forma linguística em vez de outra dependem de fatores geográficos, socioeconômicos, bem como da faixa etária, do sexo e da crença e atitude linguística do falante. Justamente por isso, documentos oficiais, como os PCN, defendem que "não se pode mais insistir na idéia de que o modelo de correção estabelecido pela gramática tradicional seja o nível padrão de língua ou que corresponda à variedade lingüística de prestígio" (BRASIL, 1998, p. 31). Entretanto, como o preconceito é decorrente do valor atribuído à variedade padrão e também do estigma associado às variedades não padrão, nomeadas como erradas pela gramática normativa da língua, destacamos que as variedades linguísticas são esquecidas e deixadas de lado como objeto de ensino na maioria das aulas de Língua Portuguesa. Contudo, vale ressaltar o enunciado dos PCN:

Para cumprir bem a função de ensinar a escrita e a língua padrão, a escola precisa livrar-se de vários mitos: o de que existe uma forma correta de falar, o de que a fala de uma região é melhor do que a de 
outras, o de que a fala correta é a que se aproxima da língua escrita, ou de que o brasileiro fala mal o português, o de que o português é uma língua difícil, ou de que é preciso consertar a fala do aluno para evitar que ele escreva errado. (BRASIIL, 1998, p. 31).

A escola precisa proporcionar um ensino da Língua Portuguesa que considere a língua como um conjunto de variedades representadas por alguns exemplos de variação linguística, visto que tudo depende da adequação ao uso.

No ensino-aprendizagem de diferentes padrões de fala e escrita, o que se almeja não é levar os alunos a falar certo, mas permitir-lhes a escolha da forma de fala a utilizar, considerando as características e condições do contexto de produção, ou seja, é saber adequar os recursos expressivos, a variedade de língua e o estilo às diferentes situações comunicativas [...] A questão não é de erro, mas de adequação às circunstâncias de uso, de utilização adequada da linguagem. (BRASIL, 1998, p. 31).

Castilho (2002), ao discorrer sobre variação linguística correlacionada ao ensino, afirma a necessidade de considerar o perfil da sociedade, dos alunos e dos professores, para que se reflita em que espaço social está se inserindo o ensino da norma de uso e como se estabelecem as atitudes a respeito da Língua Portuguesa. Com relação à sociedade nacional, o autor indica não ser homogênea, daí a dificuldade para impor o padrão linguístico de uma classe social sobre a outra. E, com relação aos professores, dentre tantas características, o autor ressalva a existência de "certo tradicionalismo" que assumem em suas práticas de ensino da Língua Portuguesa, lembrando, por fim, o quanto isso vai de encontro ao perfil dos alunos descrito pelo autor em seu texto.

O pesquisador recomenda considerar a melhoria dos profissionais de Letras, por meio de mudança no currículo desse curso. Ressaltamos que essas indagações e sugestões do autor, feitas na década de 1970, são ainda hoje pertinentes para o ensino, visto que pouca coisa mudou e a sociedade e os alunos mantêm seu caráter heterogêneo e tanto os professores quanto os currículos precisam se adaptar a tais demandas. 
Camacho (2006) também discorre a respeito da pedagogia da Língua Portuguesa. Para ele, a forma como a língua vem sendo ensinada desempenha tradicionalmente o modelo da deficiência, já que considera a variação linguística como desvio da norma culta (aquela mais próxima das classes mais privilegiadas), isso porque "o principal pressuposto da tradição normativa é que cabe à escola o papel de compensar supostas carências socioculturais" (CAMACHO, 2006, p. 69). Seria função da escola, portanto, substituir a variedade não padrão pela padrão. Para a Sociolinguística, as formas de variação de linguagem não precisam passar por um crivo valorativo, pois, como sugere o autor, são formas alternativas do sistema linguístico.

Caberia à escola, dessa forma, uma tarefa fundamental com relação à abordagem da variação linguística em sala de aula: "cumpre-lhe despertar a consciência do aluno para a adequação das formas às circunstâncias do processo de comunicação" (CAMACHO, 2006, p. 69).

Bagno (2007) aponta para a necessidade de aplicar ao ensino a pedagogia da variação linguística e sugere que essa abordagem ocorra de forma organizada. Refletindo, portanto, sobre o modo de tratar os fenômenos de variação e mudança no ensino da língua materna, o pesquisador propõe que a melhor opção seria "reconhecer que a escola é o lugar de interseção inevitável entre o saber erudito-científico e o senso comum, e que isso deve ser empregado em favor do/a estudante e da formação de sua cidadania” (BAGNO, 2007, p. 78), pois, qualquer ensino que priorize uma análise desconsiderando um desses pontos de vista - o científico ou o senso comum - pode ser considerado incompleto, além de não revelar a realidade linguístico-social do alunado. Nessa reflexão, o autor defende uma reeducação sociolinguística como papel do professor de Língua Portuguesa.

Para o autor, a reeducação sociolinguística só acontecerá quando, a partir daquilo que o aluno já sabe muito bem (ou seja, falar sua língua materna), o professor incentivá-lo a realizar reflexões a respeito da língua e conhecer os juízos de valor sociais (suas crenças) sobre a própria língua. O pesquisador propõe, destarte, que no ensino da língua materna se apresentem aos alunos as manifestações verbais por meio de suas análises, a fim de conhecer as crenças linguísticas sobre sua língua materna para manter ou transformar, quando necessário, suas atitudes linguísticas. 
Faraco (2008) discorre a respeito da situação da pedagogia da variação linguística, apontando a instituição de diferentes gêneros discursivos no ensino de Língua Portuguesa como passo importante, especialmente com relação à pedagogia da leitura e da produção de texto, já que não mais se privilegia somente um tipo - o texto literário (para a leitura) ou a redação (no caso da produção de texto) -, já que é obrigação da escola oferecer tanto a experiência da literatura quanto o convívio com os textos de ampla circulação sociocultural. Entretanto, o autor ressalta que ainda estamos muito atrasados na construção de uma pedagogia da variação linguística: "Parece que não sabemos, de fato, o que fazer com a variação linguística na escola. E o que temos feito é seguramente bastante inadequado" (FARACO, 2008, p. 176).

Segundo esse pesquisador, os documentos oficiais de diretrizes para o ensino já abordam a pedagogia da variação linguística, fato que o autor destaca como ganho para o ensino. No entanto, como ele também observa, mesmo com os documentos oficiais abordando essa pedagogia, ainda não se encontram presentes efetivamente nos livros didáticos trabalhos e atividades que abordem a variação linguística em sua complexidade.

Nos livros, os fenômenos de variação são ainda marginais e maltratados (são abordados tendo a cultura do erro como pano de fundo). Quando se fala em variedades da língua, predominam referências à variação geográfica (sem dúvida, a mais fácil de ser abordada por envolver menos preconceitos do que a variação social). No entanto, os fenômenos são aqui apresentados muito mais de uma maneira anedótica do que como expressões lingüísticas da história das comunidades de cada região. (FARACO, 2008, p. 177).

Diante disso, o autor assevera a não existência de uma pedagogia adequada à variação linguística e explica: "Talvez porque não tenhamos ainda, como sociedade, discutido suficientemente, no espaço público, nossa heterogênea realidade lingüística, nem a violência simbólica que a atravessa" (FARACO, 2008, p. 177). Sabemos que a Língua Portuguesa é heterogênea, extremamente diversificada, entretanto, o problema no ensino dessa língua, como sugere o autor, não está na diversidade da língua, mas no modo de lidar com a diversidade. 
Dentro da diversidade linguística, as variedades (ou normas) se equivalem com relação à estrutura, segundo Faraco (2008), pois são igualmente organizadas e complexas. Todavia, não se equivalem socialmente e, como vão recebendo diferentes avaliações sociais, essas avaliações podem ser positivas ou negativas (desprestigiadas ou até estigmatizadas).

\section{O Preconceito Linguístico}

Com relação à adequação da linguagem ao uso e à avaliação social da linguagem, é necessário um trabalho frequente nas escolas a fim de evitar o preconceito linguístico, considerando as crenças e atitudes linguísticas em contexto escolar, pois o essencial não é, somente, ensinar o aluno a "falar certo" de acordo com a norma padrão, imposta pela gramática normativa, mas mostrar que ele pode escolher a melhor forma de linguagem de acordo com o contexto de produção.

O preconceito, por mais que seja uma atitude negativa do indivíduo sobre um determinado objeto ou conceito, é um reflexo do seu ambiente. Crochík (2006) já afirmara, a respeito do preconceito, que "sua manifestação é individual, assim como responde às necessidades irracionais do indivíduo, mas surge no processo de socialização como resposta aos conflitos aí então gerados" (CROCHÍK, 2006, p. 13).

Destacamos também a existência do preconceito com relação à língua, ou seja, uma atitude negativa ao uso de variedades estigmatizadas de nossa língua. Os falantes, diante desse fenômeno de variação, que envolve sua identidade e seus valores socioculturais, revelam-se mais facilmente, mostrando sua atitude, seus julgamentos.

O problema e a propagação do preconceito linguístico, entretanto, não está na diversidade social e geográfica do território brasileiro, mas na maneira como tratamos essa diversidade: “O problema está nas formas como lidamos com essa diversidade. O problema está na forma como representamos para nós essa diversidade. O problema está nas imagens saturadas de valores negativos que temos de nós como falantes" (FARACO, 2008, p. 181).

Isso comprova a necessidade de abordar a variação linguística na escola, de preservar o respeito pelas diferenças linguísticas e de mostrar que, ao analisarmos a fala, não encontramos "erros", mas variedades. 


\section{A Pesquisa: o conteúdo da variação linguística e sua presença nas salas de aula}

Esta pesquisa objetiva investigar as atitudes linguísticas dos alunos de Língua Portuguesa a respeito do uso da variação linguística e de sua abordagem em sala de aula, observando se a atitude revela um preconceito a respeito dessa abordagem. A coleta de dados, para a constituição do corpus, realizouse em duas escolas estaduais de Londrina, uma localizada no centro (escola A) e outra na zona rural (escola B). Obtivemos nove informantes da série final do Ensino Fundamental de cada instituição, nomeados Inf. 01 até Inf. 18. Dessa forma, a indicação de trechos do corpus se deu a partir de abreviaturas de forma que "Inf. “ corresponde a informante, "Q" corresponde à questão e "L" corresponde à linha da transcrição em que se encontra o trecho.

O questionário possui quatro questões elaboradas a partir do projeto Crenças e Atitudes Linguísticas: um estudo da relação do Português com línguas de contato (AGUILERA, 2009). As questões do corpus são 1. "A escola deveria ensinar modos diferentes de falar o Português? Por quê?"; 2. "Quais modos diferentes, em sua opinião?”; 3. "Em que lugares você ouve este(s) modo(s) diferente(s)? Comente."; e 4. "O professor de Português mostra os diferentes modos de falar durante a aula?"

As questões de 1 a 3 têm por finalidade discutir a respeito da pedagogia da variação linguística. Nessa sequência de perguntas, investigamos a opinião dos alunos sobre a abordagem da variação linguística em sala de aula, pois a pedagogia da variação linguística indica que se trabalhe, de forma conjunta, a norma padrão e as normas não padrão da Língua Portuguesa.

Na primeira questão, notamos uma discordância de crenças entre os alunos da escola central e da rural, como verificamos no Gráfico 1. Dos nove informantes de cada escola, sete da escola central acham que não se deve abordar a variação linguística em sala de aula, seja por acreditarem que a língua sempre vai mudar, seja por afirmarem ser o ensino da norma padrão suficiente, principalmente porque o uso da língua padrão permite a manutenção da comunicação entre os falantes. A existência dessa manutenção na linguagem em uso, apontada por Castilho (2002), ocorre por causa da norma prescritiva, combinação da objetiva e subjetiva, como uma determinação dos usos linguísticos do grupo de prestígio: "Porque sempre 
vai mudar, né? Ter uma gíria nova. Eu acho que não há necessidade.” (Inf. 02, Q1, L270-271); "Porque o que eles estão ensinando, já é muito bom, aprende bastante. O Português aqui é muito bom. O professor aqui é bem rígido, pega bastante no pé. Eu aprendi bastante." (Inf. 03, Q1, L422-424); "Ah, eu acho que deveria ter um padrão né. [...] pra ficar mais fácil." (Inf. 07, Q1, L994-996) ${ }^{1}$.

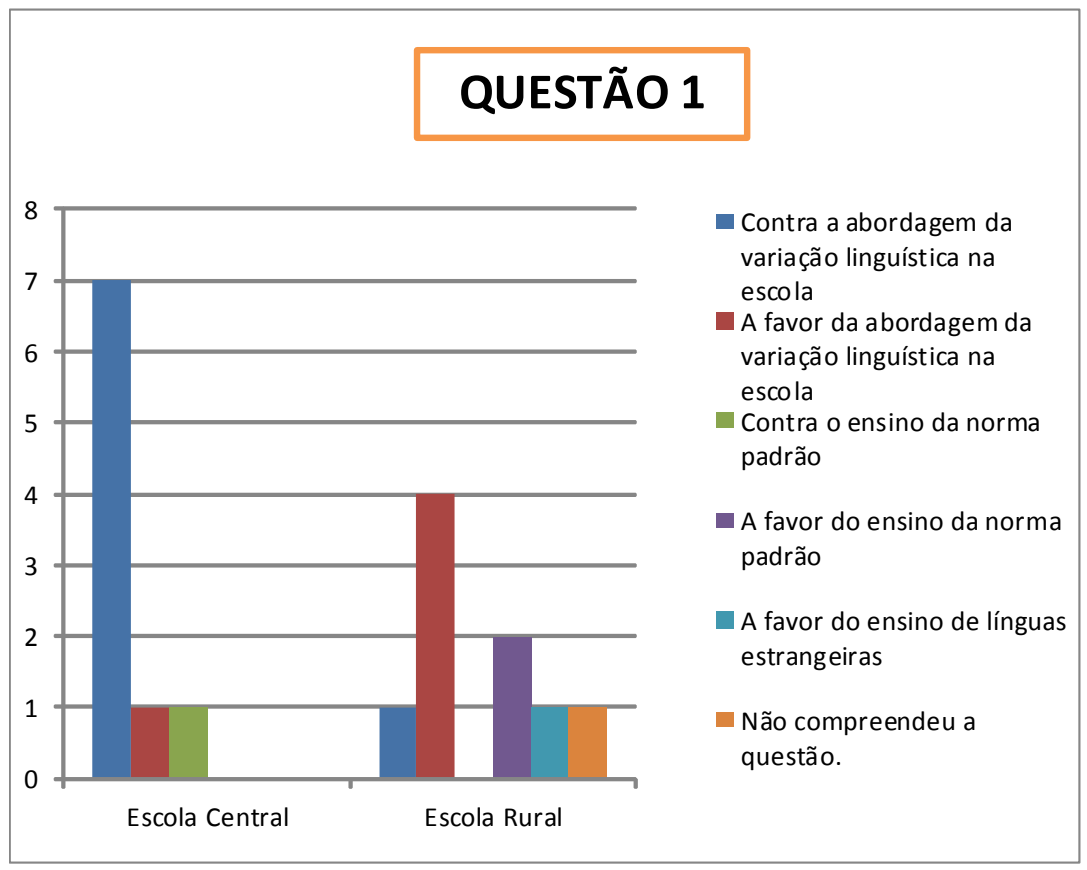

Gráfico 1 - A escola deveria ensinar modos diferentes de falar o português? Por quê?

Somente dois informantes da escola central afirmam que a escola deve abordar a variação linguística. O primeiro aponta a necessidade de

\footnotetext{
${ }^{1}$ A transcrição na integra das entrevistas com os dezoito informantes está disponível em <http://migre.me/qHx7o $>$.
} 
conhecer um pouco de cada modo diferente de falar, quando afirma: "Porque deveria reconhecer na hora que a outra pessoa falar alguma coisa" (Inf. 01, Q1, L116). O outro informante a favor da abordagem da variação linguística, na verdade, sugere que a escola não deveria ensinar a norma padrão, justifica que ela não é muito utilizada, como explica: "Acho que o Português que a gente aprende na escola é um Português mais correto, né. Só que esse, não devia, porque as pessoas não usam na rua, eu acho. [...] Porque essa forma (norma padrão) a gente não usa muito sabe. É uma coisa assim que é pouco usada no dia-a-dia." (Inf. 08, Q1, L1151-1157).

Quando analisamos as respostas dos alunos da escola rural, em comparação com os da escola central, apuramos o oposto, visto que, dos nove informantes da escola rural, cinco defendem a abordagem da variação linguística na escola ao responderem afirmativamente que os modos diferentes devem ser tratados em sala de aula. Entretanto, ao justificarem suas respostas, somente quatro realmente aceitam essa abordagem, alegando haver necessidade de combater o preconceito linguístico, abordando as variedades linguísticas e a norma padrão: "Porque a escola ensina só uma maneira de falar e tem várias maneiras, não é só uma." (Inf. 12, Q1, L1738) e "Pra pessoa ter uma diferença, eu acho que seria até bom, porque tem muito Português que é quase igual ao que nós falamos errado. Acho que é bom ter.” (Inf. 18, Q1, L2605-2606). Ressaltamos que somente quatro informantes conseguem realmente aceitar a abordagem da variação, mas, ainda assim, é um número maior do que na escola central.

Ao analisar a segunda questão, notamos que os tipos de variedades mais citadas estão "gírias" e "sotaques": "gírias de outros Estados" (Inf. 01, Q2, L122); “Os sotaques do norte, sul, central.” (Inf. 07, Q2, L1000); “As pessoas que falam gírias” (Inf. 08, Q2, L1161); “Gíria” (Inf. 12, Q2, L1742); "A gíria, sotaque diferente, tipo baiano, nordestino" (Inf. 18, Q2, L2610).

$\mathrm{Na}$ questão 3, por sua vez, encontramos os lugares ou as situações em que eles reconhecem variedades linguísticas, tais como: "Nordeste” (Inf. 01, Q3, L129); "Música de rap... E também na escola” (Inf. 03, Q3, L435); “No meu bairro também tem muita gente que fala na gíria" (Inf. 04, Q3, L578); "Em cada cidade que você vai, muda um pouquinho" (Inf. 07, Q3, L1004); "Mais em roda de amigos, em lugares em que você fica mais chegado às pessoas" (Inf. 08, Q3, L1165); "Em outras regiões, porque tem sotaque” 
(Inf. 10, Q3, L1450); “Em televisão, quando tem um pessoal bem diferente" (Inf. 11, Q3, L1596); "Ah, tem gente que vem de fora e fala o português, quem vem do Japão fala o português diferente" (Inf. 13, Q3, L1894-1895); "Cada lugar tem um jeito" (Inf. 14, Q3, L2034); "Só os jornalistas mesmo" (Inf. 15, Q3, L2175); “A minha família fala diferente e cada um fala de um jeito” (Inf. 16, Q3, L2320); “Só na escola” (Inf. 17, Q3, L2465); “Área de trabalho, na escola, nos lugares que a gente vai né” (Inf. 18, Q3, L2615).

Ressaltamos, como mais reconhecidas, as variedades social e geográfica, uma vez que, no Brasil, a amplitude territorial permite ao falante notar a diferença na linguagem de outra região e a heterogeneidade social permite observar e diferenciar a linguagem culta e a popular.

No entanto, dois informantes favoráveis, na questão 1, à abordagem da variação linguística na escola, mostraram-se, na segunda questão, leais somente ao ensino da norma padrão, pois julgam que falam por meio da norma culta, alegando que este ensino deve ser abordado em sala: "O modo certo” (Inf. 17, Q2, L2461); “A escola tinha que ensinar o português correto, o português que é falado, tipo assim, entre a gente. Ensinar a cultura, essas coisas que a escola tinha que ensinar mais" (Inf. 12, Q2, L1745-1746).

Apenas um, na questão 1, não prevê a abordagem da variação no ensino de Língua Portuguesa, mesmo sabendo que, em outras regiões, são utilizados modos diferentes de falar o Português, como o aluno explica: "Eu acho que não, que de outras regiões assim está certo que falam diferente o Português, mas geralmente não se deve ensinar" (Inf. 14, Q1, L2027-2028).

Por fim, um entrevistado da escola rural, quando questionado sobre a variação na escola, por não compreender a que se referem os "modos diferentes de falar o Português", responde que deveriam ser ensinadas mais línguas, como o inglês e o espanhol: "Porque tem que ensinar, pra nós sabermos mais as coisas, né, tipo, se a gente for pra outro lugar, outro país, pra passear, tem que saber as coisas...” (Inf. 13, Q1, L1881-1882). Esse informante relaciona "coisas" às línguas estrangeiras: "inglês, espanhol, coisas de outros países” (Inf. 13, Q2, L1888). Diante disso, a entrevistadora refez a questão, perguntando sobre os modos de falar do Português, mas o aluno mantém-se sem saber do que se trata a questão, pois responde dessa forma: 
P.: Quais modos diferentes em sua opinião?

Inf. 13: Inglês, espanhol, coisas de outros países.

P.: Mas e os modos de falar o Português?

Inf. 13: Ah, sei lá, acho que tem que ensinar.

$$
\text { (Inf. 13, Q2, L1887-1890). }
$$

Dessa forma, mesmo que ele se mostre favorável à abordagem da variação na escola, por fim, ao considerar sua resposta, não podemos realmente afirmar que o informante 13 compreendeu a questão.

Observamos que, mesmo quando conhecem ou identificam as variedades linguísticas, poucos são a favor da abordagem dessa modalidade da língua em sala de aula. O resultado apontado por esses dados, a partir das atitudes sobre a abordagem da variação linguística, vai ao encontro do exposto por Faraco (2008), quando afirma que a pedagogia da variação, mesmo já presente nos documentos oficiais de diretrizes para o ensino, ainda não é uma ideia fixa para os indivíduos, como o professor, que estenderá o assunto até o alunado.

Consoante Faraco (2008), ainda não existe uma pedagogia adequada à variação, talvez por não termos discutido, suficiente e publicamente, a heterogênea realidade linguística existente no Brasil, nem o preconceito linguístico gerado por situações de prestígio social sobre a norma padrão. $\mathrm{O}$ autor afirma que já se reconhece a heterogeneidade linguística na escola, mas o modo de lidar com ela, permanece um problema. Como observamos, a maioria dos alunos reconhece a existência da variação, mas nem todos são favoráveis à sua abordagem e uso.

$\mathrm{Na}$ Questão 4 (“O professor de Português mostra os diferentes modos de falar durante a aula?"), interrogamos os alunos a fim de saber se algum professor de Português já havia tratado da variação linguística em sala de aula, para observar se uma possível introdução da pedagogia da variação já vem sendo inserida nas escolas. Dos dezoito entrevistados, quatro responderam que o professor não comenta sobre a variação do Português e, desses quatro, um utiliza a norma padrão para se justificar: "Ele (o professor de Português) mostra, tipo assim, como que é o correto.” (Inf. 18, Q4, L2619, grifo nosso). Dessa forma, quando questionado se o professor aborda a variação linguística, ele responde afirmativamente, mas pensando na norma prescritiva. 
Um informante responde afirmativamente, mas não entende a pergunta, pois, quando comenta sobre as variedades que o professor aborda em sala de aula, confunde modo de falar com conjunções adversativas, como observamos em seus exemplos: "modo que eu comecei a utilizar foi o "porém", "no entanto", que eu aprendi bastante com a professora." (Inf. 03, Q4, L441-442).

Enfim, das dezoito respostas, somente treze foram realmente afirmativas. Nesses casos, os entrevistados explicam suas respostas, relacionando os modos diferentes de falar o Português com os termos gírias, sotaques, modo coloquial, modo de falar com os amigos ou, ainda, o modo de falar de antigamente. Dentre eles, um informante consegue marcar que existem as variedades e a norma culta: "Eu uso bastante o modo coloquial, mas também tento o modo culto.” (Inf. 06, Q4, L871). Essa questão, portanto, também revela a facilidade em perceber as variedades social e geográfica. Podemos verificar que o estudo da variação linguística já se faz presente na escola, de acordo com o afirmado pelos alunos, mas ainda não o suficiente, visto que nem todos conseguem identificar as variedades de fato.

\section{Considerações Finais}

Investigamos a atitude dos alunos frente à abordagem da variação linguística na sala de aula, considerando as crenças dos informantes para analisar os dados. O percurso dessa pesquisa apresentou, sobretudo, que não só a língua é viva e pode estar sempre suscetível a mudanças, como também que os falantes reconhecem essa heterogeneidade da língua.

Os resultados obtidos mostraram as atitudes positiva e negativa dos informantes com relação à abordagem da variação linguística na escola. Observamos uma divergência entre os alunos da escola central e da escola rural, pois, enquanto a maioria dos alunos da escola central apresentou atitude negativa, grande parte dos alunos da escola rural revelou atitude positiva. Esse dado pode resultar do fato de os alunos da escola central manterem contato mais frequente com a norma culta da Língua Portuguesa, enquanto os alunos da escola rural terem maior contato com as variedades menos prestigiadas do que com a norma culta, por isso não creem tanto na necessidade de assimilar a norma padrão quanto os alunos da escola central. 
Essa questão, portanto, indica ser imperativo o trabalho com a Língua Portuguesa sob a perspectiva da pedagogia da variação linguística, proposta por Faraco (2008), pois os alunos que apresentaram atitude negativa, bem como os alunos que revelaram atitude positiva, precisam compreender a importância do trabalho com a norma padrão em conjunto com as variedades, sem desmerecer ou prestigiar nenhuma.

Averiguamos, também, uma recente abordagem da variação linguística nas instituições escolares, mesmo que restrita, considerando a capacidade dos informantes em afirmar que os diferentes modos de falar são mostrados pelos professores em sala de aula, apresentando, como exemplo, as gírias, os sotaques, o modo coloquial e o modo de antigamente.

Mesmo sabendo que a Língua Portuguesa é composta de muitas variedades, e da conscientização dos alunos sobre elas, nem sempre esse conhecimento é transmitido na escola, pois, como verificamos, nem todos os alunos acreditam ser papel da escola tratar da variação linguística em sala de aula. A instituição escolar não está desconstruindo o estigma que os alunos constroem sobre a própria língua antes de frequentar um contexto escolar. Santos (1996) discute tal questão e afirma que a escola deve aprimorar as crenças a respeito da Língua Portuguesa, adquiridas antes da escola. "Antes de ingressar na escola o aluno é advertido, em maior ou menor grau, de que há objetos lingüísticos absolutamente 'certos' e objetos lingüísticos absolutamente 'errados'.” (SANTOS, 1996, p. 108).

Podemos afirmar que já há uma profícua pesquisa na área da Sociolinguística Educacional apontando a necessidade de abordar a variação da língua na escola, entretanto, o ambiente escolar ainda não absorveu completamente as pesquisas realizadas no ambiente acadêmico. Segundo Faraco (2008), ainda não existe uma pedagogia adequada à variação linguística, talvez por não termos discutido, suficiente e publicamente, a heterogênea realidade linguística existente no Brasil, nem o preconceito linguístico gerado por situações de prestígio social sobre a norma padrão. $\mathrm{O}$ autor afirma, sobretudo, que já se reconhece a heterogeneidade linguística na escola, mas o modo de lidar com essa diversidade permanece um problema. Como observamos, a maioria dos alunos reconhece a existência da variação, mas nem todos são favoráveis à sua abordagem e uso. 


\section{Referências}

AGUILERA, V. de A. Crenças e atitudes linguísticas: um estudo da relação do português com línguas de contato. 2009. [Projeto].

BAGNO, M. Nada na língua é por acaso: por uma pedagogia da variação lingüística. São Paulo: Parábola, 2007.

BIBER, D. Variation across speech and writing. Cambridge; New York:

Cambridge University Press, 1988.

BRASIL. Secretaria de Educação Fundamental. Parâmetros Curriculares Nacionais: terceiro e quarto ciclos do ensino fundamental: Língua Portuguesa. Brasília: MEC/SEF, 1998.

CAMACHO, R. G. A variação lingüística. In: SÃO PAULO Estado. Secretaria da Educação. Coordenadoria de Estudos e Normas Pedagógicas. Subsídios à proposta curricular de língua portuguesa para o $1^{\circ}$ e $2^{\circ}$ graus: coletânea de textos. v. I. São Paulo: SE/CENP, 1988. p. 29-413.

CAMACHO, R. G. Sociolingüística: parte II. In: MUSSALIM, F.; BENTES, A. C. (Orgs.). Introdução à lingüística: domínios e fronteiras. v. 1. 6. ed. São Paulo: Cortez, 2006. p. 49-75.

CAMARA JR., J. M. Estrutura da Lingua Portuguesa. Petrópolis: Vozes, 1970.

CASTILHO, A. T. Variação dialetal e ensino institucionalizado da língua portuguesa. In: BAGNO, M. (Org.). Lingüistica da norma. São Paulo: Loyola, 2002. p. 27-36.

CASTILHO, A. T. de. Nova Gramática do Português Brasileiro. São Paulo: Contexto, 2010.

CHAFE, W. Properties of spoken and written language. Berkeley; Washington: Center for the study of writing; U. S. Dept. of Education Resources Information Center, 1987. 
CHAFE, W. Discourse, consciousness and time: the flow and displacement of conscious in speaking and writing. Chicago: Chicago University Press, 1994.

COSERIU, E. Teoria da linguagem e lingüística geral: cinco estudos. Tradução Agostinho Dias Carneiro. Rio de Janeiro: Presença, 1987 [1921].

CROCHÍK, J. L. Preconceito, indivíduo e cultura. 3. ed. São Paulo: Casa do Psicólogo, 2006.

FARACO, C. A. Norma-padrão brasileira: desembaraçando alguns nós. In: BAGNO, M. (Org.). Linguistica da norma. São Paulo: Loyola, 2002. p. 37-61.

FARACO, C. A. Norma culta brasileira: desatando alguns nós. São Paulo: Parábola, 2008.

MARCUSCHI, L. A. Fala e escrita no continnum tipológico. Recife: UFPE, 1997.

SANTOS, E. dos. Certo ou errado?: atitudes e crenças no ensino de língua portuguesa. Rio de Janeiro: Graphia, 1996.

TANNEN, D. Analysing discourse: text and talk. Washington: Georgetown University Press, 1982.

Recebido em: 20/11/2014 Aceito: 26/04/2015 